\title{
Alcohol consumption and intoxication among people involved in police-recorded incidents of violence and disorder in non-metropolitan New South Wales
}

\author{
Shelley Rowe \\ School of Medicine and Public Health, University of Newcastle, New South Wales
}

John Wiggers, Melanie Kingsland

School of Medicine and Public Health, University of Newcastle and

Hunter New England Local Health District, NSW Health

\section{Craig Nicholas}

Hunter New England Local Health District, NSW Health

\section{Luke Wolfenden}

School of Medicine and Public Health, University of Newcastle and NSW Cancer Institute

A ssaults, motor vehicle crashes and disorder associated with alcohol use incur a considerable cost to individuals and to communities. ${ }^{1}$ In Australia about 1,676 deaths and 48,910 hospitalisations are attributed to alcohol intoxication annually, ${ }^{2}$ with alcohol-related crime estimated to account for more than $40 \%$ of such harm. ${ }^{2}$ Such harm may also elevate community fear of crime, contributing to increased anxiety and ill-health. ${ }^{3}$

The nexus between alcohol consumption and crime is particularly apparent with regard to the offences of violence and public disorder. For example, research suggests that up to $50 \%$ of violent offences and up to $70 \%$ of public disorder offences are alcohol-related. ${ }^{4-6}$ The apparent pervasiveness of alcohol intake prior to involvement in violence incidents appears to apply to both victims and perpetrators, ${ }^{7}$ suggesting that alcohol consumption is a risk factor regardless of the alcohol consumer's role in the incident.

Research conducted primarily in metropolitan areas has identified temporal and situational characteristics of alcohol-related crime. In particular, research suggests that the consumption of alcohol on weekend evenings, on licensed premises, and to intoxication, are disproportionately associated with criminal incidents. ${ }^{4-6,8,9}$

Despite such consistency, a limited number of studies suggest that the prevalence and characteristics of alcohol-related crime varies between geographic areas. For example, the rate of alcohol-related violence incidents in Britain was reportedly higher in inner city and urban areas compared to rural areas. ${ }^{8}$ Conversely, in Australia and North America, rates of alcohol-related harm, including crime, were higher in non-metropolitan areas compared to metropolitan areas. ${ }^{2,4,10-13}$ While no peer-reviewed studies could be located that described geographic differences in the characteristics of alcohol-related crime, within the 'grey' literature in New South Wales (NSW), crime profiles provide an indication of the geographic variability in the characteristics of police-recorded alcoholrelated assaults. ${ }^{14}$ These profiles indicate that licensed premises are more commonly the location of such assaults in city areas compared to regional areas. ${ }^{14}$

\begin{abstract}
Objective: To describe, based on routinely recorded police data, the prevalence and characteristics of alcohol consumption among people involved in violence and disorder incidents in non-metropolitan New South Wales (NSW).

Methods: A descriptive analysis was conducted of people involved in violence and disorder incidents over 24 months (2003-05) across 21 non-metropolitan police commands. The prevalence of alcohol involvement was reported as: the annual population rate of people involved in incidents who had consumed alcohol; the proportion of people involved in such incidents who had consumed alcohol; and the proportion of such people who were intoxicated. Variation in alcohol involvement was described by: geographic area; day of week; time of day; and location alcohol was last consumed.
\end{abstract}

Results: Annually, one in 118 people in the population consumed alcohol prior to involvement in a violence incident, and one in 476 people did so prior to a disorder incident. At least $71 \%$ of such people were intoxicated. Late Saturday evening was the peak time for alcohol involvement. Prior drinking in private residences and licensed premises was associated with violence and disorder incidents (respectively). The prevalence of alcohol consumption rose with increased geographic remoteness. All characteristics displayed geographic variation.

Conclusions: The high prevalence of alcohol consumption, particularly intoxication, in violence and disorder incidents represents a significant public health issue for non-metropolitan NSW. Implications: Geographic variability in the prevalence and characteristics of alcoholrelated crime suggests a need for locally targeted, yet evidence-based, interventions to reduce such harm.

Key words: alcohol, crime, violence, disorder, non-metropolitan

Aust NZ J Public Health. 2012; 36:33-40 doi: 10.1111/j.1753-6405.2011.00773.x 
Limited data suggest that further variability in the prevalence of such harms exists within non-metropolitan areas. For example, NSW crime profiles suggest that the population rate of alcohol-related assault is inversely related to population density. ${ }^{14}$ However, only one published peer-reviewed study that examined differences in the prevalence of alcohol-related crime between non-metropolitan areas could be identified, with this research utilising Western Australian crime data from 1991/92. ${ }^{11}$ Furthermore, no peer-reviewed or 'grey' literature were identified that describe the geographic variability of alcohol-related violence and disorder incidents in non-metropolitan areas by day of the week, time of day or place of alcohol consumption. Differences between metropolitan and nonmetropolitan areas, and between different non-metropolitan areas, in the prevalence and characteristics of such harm could be expected, given differences between these areas in determinants and indicators of alcohol-related harm such as the density of alcohol outlets, rates of at-risk alcohol consumption, rates of alcohol-related illness and injury, and socio-cultural characteristics. ${ }^{15,16}$

A further, and potentially more fundamental, limitation of research estimating the prevalence and characteristics of alcoholrelated harm is that such research is largely dependent on the analysis of routinely recorded agency data, such as hospital admissions and police-recorded incidents. ${ }^{17}$ The utility of such data to serve as measures of alcohol-related harm is limited by recording inconsistencies arising from the requirement for a judgement to be made regarding alcohol involvement in the absence of specific and standardised criteria, the need to make such a judgement while dealing with the immediate complexities of the situation, and the absence of systematic processes for the consistent recording and retrieval of such information within and across agencies and sites. ${ }^{17-19}$ In light of these limitations, governments, the liquor industry and researchers have recommended that agencies adopt explicit criteria for defining alcohol involvement, the degree of alcohol impairment, and the alcohol consumption location, and to adopt procedures for the routine collection of such information for a broad range of harms. ${ }^{18,19}$

The feasibility of police collecting such information has previously been reported in a limited number of small area studies. ${ }^{5,6}$ More recently, Wiggers et $\mathrm{al}^{20}$ reported on the introduction, on a jurisdiction-wide basis, of procedures for the routine collection and recording of information by police regarding alcohol involvement in recorded incidents. The initiative, implemented in NSW, required police to record whether or not a person involved in an incident had consumed alcohol prior, and, if so, to determine and record their intoxication status based on observable signs of intoxication ${ }^{21}$ and the last location where alcohol was consumed by the person prior to the incident. To facilitate consistency of recording of this information organisational change strategies were implemented, including: a specific and standardised definition and method for collecting and recording information; training of all officers in data collection and recording; and, the implementation of monitoring and performance feedback protocols. During the 12-month adoption period, complete alcohol data were recorded for at least $87 \%$ of incidents..$^{20}$

The adoption by police of enhanced recording of alcohol involvement in criminal incidents provides an opportunity for greater understanding of such harm in the community. Given the paucity of recently published peer-reviewed studies of alcoholrelated crime in non-metropolitan areas, a study was undertaken to describe the prevalence and characteristics of alcohol involvement in police-recorded violence and disorder incidents in non-metropolitan areas of NSW.

Table 1: Number, alcohol consumption status and annual population rate of people involved in violence and disorder incidents that followed the consumption of alcohol (July 2003 to June 2005), by geographic area.

\begin{tabular}{|c|c|c|c|c|c|c|}
\hline \multirow[t]{2}{*}{ Geographic area } & \multirow{2}{*}{$\begin{array}{l}\text { Population }^{22} \\
\text { Number }\end{array}$} & \multirow{2}{*}{$\begin{array}{l}\text { People involved in } \\
\text { incidents } \\
\text { Number }\end{array}$} & \multirow{2}{*}{$\begin{array}{c}\text { People with complete } \\
\text { alcohol data (yes or no) } \\
\text { Number }(\%)\end{array}$} & \multicolumn{3}{|c|}{ People who consumed alcohol prior to incident } \\
\hline & & & & $\begin{array}{c}\text { Number } \\
\text { consumed (\%) }\end{array}$ & $\begin{array}{l}\text { People per } \\
1,000 \text { (annual } \\
\text { standardised) }\end{array}$ & $\begin{array}{c}\text { Number } \\
\text { intoxicated (\%) }\end{array}$ \\
\hline \multicolumn{7}{|l|}{ Violence } \\
\hline Regional cities & 457,122 & 17,146 & $15,504(90.4)$ & $5,013(32.3)$ & 5.7 & $3,448(68.8)$ \\
\hline Outer regional & 250,375 & 11,900 & $10,823(91.0)$ & $4,717(43.6)$ & 10.7 & $3,402(72.1)$ \\
\hline Remote & 29,440 & 3,765 & $3,403(90.4)$ & $1,726(50.7)$ & 31.5 & $1,264(73.2)$ \\
\hline Very remote & 5,585 & 2,236 & $1,994(89.2)$ & $1,136(57.0)$ & 103.1 & $883(77.7)$ \\
\hline All areas & $1,409,475$ & 63,687 & $57,919(90.9)$ & $22,002(38.0)$ & 8.5 & $15,669(71.2)$ \\
\hline \multicolumn{7}{|l|}{ Disorder } \\
\hline Inner regional & 666,953 & 3,977 & $3,798(95.5)$ & $2,866(75.5)$ & 2.4 & $2,505(87.5)$ \\
\hline Outer regional & 250,375 & 1,973 & $1,863(94.4)$ & $1,349(72.4)$ & 3.1 & 1,191 (88.3) \\
\hline Remote & 29,440 & 389 & 369 (94.9) & $253(68.6)$ & 4.7 & $224(88.5)$ \\
\hline Very remote & 5,585 & 318 & $280(88.1)$ & $168(60.0)$ & 15.3 & $156(92.9)$ \\
\hline All areas & $1,409,475$ & 7,741 & $7,310(94.4)$ & 5,359 (73.3) & 2.1 & 4,677 (87.3) \\
\hline
\end{tabular}




\section{Method}

\section{Design, setting and sample}

A descriptive analysis of people involved in police-recorded incidents of violence and disorder from 1 July 2003 to 30 June 2005 was conducted. The incidents occurred in 21 non-metropolitan NSW police commands ( $26.3 \%$ of all NSW commands).

The population of the study area was approximately 1.4 million (20.8\% of the NSW population). ${ }^{22}$ Males constituted $50.0 \%$ of the population, and the modal age-group was 40 to 44 years. Across NSW and Australia, males constituted 49.6\% and 49.7\% (respectively) of the population and the modal age-group of these populations was 40 to 44 years. ${ }^{22}$

\section{Data collection procedure}

All NSW Police Force officers are required, as part of routine operational policing practice, to enter details of attended or reported criminal incidents into a statewide database. For each incident, officers record the offence category, ${ }^{23}$ the address, date and time of the incident, and the particulars of persons involved, including their date of birth, gender and the nature of their involvement. In 2002, it became mandatory for all police in the study area to collect and record prior alcohol consumption information of all drivers, victims and alleged offenders. ${ }^{20}$

\section{Measures}

The geographic location of each incident was classified according to the postcode area using the Australian Standard Geographical Classification (regional cities, inner regional, outer regional, remote, and very remote). ${ }^{22}$ Figure 1 and Table 1 show the distribution of the postcode areas and the population of each geographic area.
The recording and classification of criminal incidents vary across each Australian state and territory. According to NSW Police Force recording procedures, a criminal event may contain one or more criminal incidents, all of which are linked by the people involved, the location and the occurrence across an uninterrupted period of time. ${ }^{23} \mathrm{~A}$ criminal incident is a single occurrence of a single offence category. ${ }^{23}$ Consistent with previous research, ${ }^{4,5}$ 'violence' incidents included: common assault; actual bodily harm; grievous bodily harm; assault officer; and, shoot with intent other than to murder. With the exception of sexual assaults, all assaults were included within this definition. 'Disorder' incidents incorporated offensive conduct and offensive language..$^{23}$ Being intoxicated in public is not an offence in NSW. Offences relating to the possession of alcohol in public places are separately classified within NSW Police Force offence categories.

Age of each person was calculated from the date of birth and incident date recorded within the database.

The day of the week the incident occurred was determined from the date of the incident. The time of the day the incident occurred was recorded as hour:minutes.

For each victim or alleged offender involved in an incident, police recorded whether the person had consumed alcohol prior to the incident (yes, no or not known) based on the direct testimony of the person involved and/or the officer's observation of signs of alcohol consumption. ${ }^{20}$ 'Not known' was the default response for any person not spoken to by an officer or when prior alcohol consumption was not ascertained.

If alcohol was consumed by the person prior to their involvement in the incident, their level of intoxication (not, slightly, moderately, well or seriously affected) was recorded by police. ${ }^{20}$ The level of intoxication was based on the officer's assessment of a range

Figure 1: Geographic areas shaded by remoteness classification (areas not shaded were outside the study area).

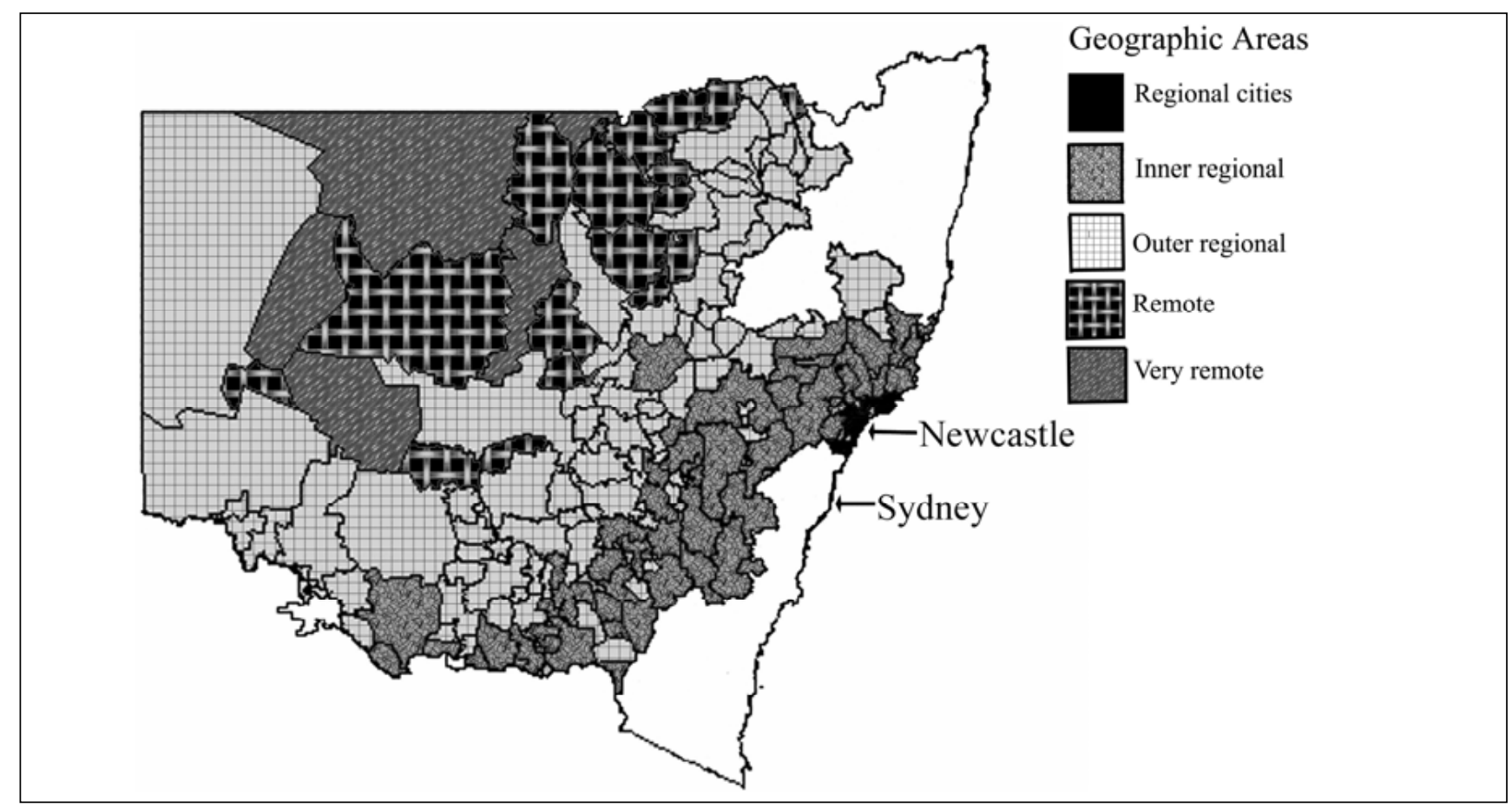


of appearance and demeanour indicators, including sweating, impaired psychomotor control and slurred speech. ${ }^{21}$ 'Intoxicated' incorporated the response categories of moderately, well and seriously affected as such levels were consistent with the symptoms of intoxication described in NSW government guidelines. ${ }^{24}$

For all persons recorded as having consumed alcohol prior to the incident, officers recorded the self-reported last place of consumption (licensed premises, home/private residence, public place, other or not known). 'Other' incorporated drinking at licensed functions, restaurants, and locations not otherwise listed. 'Not known' was the default location for persons who refused or failed to provide a response, or where information was not recorded.

\section{Data exclusion}

Individuals involved in each criminal event were uniquely identified by their recorded date of birth and gender. To avoid replication of information, individuals were counted only once for any given incident (violence or disorder) within a criminal event.

Records of people were excluded from the analysis if they were involved in incidents for which postcodes were not recorded, or if their prior alcohol consumption status or intoxication was recorded as 'not known'. Records of people whose gender or date of birth was unknown were also removed from the analysis of the prevalence of alcohol involvement.

\section{Analyses}

Three indicators were calculated to describe the prevalence of alcohol involvement in violence and disorder incidents.

1. The annual average population rates of people who consumed alcohol prior to involvement in violence and disorder incidents were calculated for the study area and for each geographic area (persons per year per 1,000 population). ${ }^{22}$ Direct age and gender standardised rates were calculated using: 0-14, 15-24, 25-34, 35-44, 45-54, 55-64, and 65 years and over age-groups.

2. The proportions of people involved in violence and disorder incidents who had consumed alcohol prior to the incident were calculated for the study area and for each geographic area.

3. The proportions of intoxicated people involved in violence and disorder incidents were calculated for each geographic area using the total number of people who consumed alcohol prior to involvement in the violence or disorder incidents as the denominator.

Separate logistic regression models (generalised linear models with the binomial proportion as the outcome) were used to determine the geographic variability in each of the three indicators. For each model, 'regional cities' was the reference group and the person's age and gender were entered to control for these effects. Except for analyses of the annual population rates, in which age was categorised in age-groups, age was treated as a continuous variable. The likelihood ratio statistic of the variable geographic area from each model is reported as LR $\chi^{2}(\mathrm{df})$. For each geographic area, age and gender adjusted odds ratios were calculated.

The proportion of people who consumed alcohol preceding their involvement in a violence or disorder incident was calculated for each day of the week for the overall study area and each geographic area. Similarly, the proportion of people who consumed alcohol preceding their involvement in such incidents was calculated for each three hour period for the overall study area and each geographic area. Geographic variability in the proportion of persons who consumed alcohol preceding their involvement in violence and disorder incidents by day of week and by time of day were assessed using separate multiple logistic regression models. Indicator variables in each model were day of week and time of the day with 'Saturdays' and ' $12-3$ am' used as reference groups. Odds ratios were calculated to compare the prevalence of prior alcohol consumption between days of the week and times of day.

Separate chi-square tests $\left(\chi^{2}(\mathrm{df})\right)$ examined differences between geographic areas in the reported last place of alcohol consumption for people who consumed alcohol preceding their involvement in violence and disorder incidents.

\section{Results \\ Sample}

Table 1 displays the recorded number and alcohol consumption status of people involved in violence and disorder incidents in the study area during the study period.

\section{Annual population rate of involvement in incidents that followed the consumption of alcohol}

Geographic area was a significant predictor variable in the models for the annual population rate of involvement in violence $\left(\operatorname{LR} \chi^{2}(4)=7,398.31, p<0.001\right)$ and disorder $\left(\operatorname{LR} \chi^{2}(4)=1,640.81\right.$, $p<0.001)$ incidents following the consumption of alcohol. Such rates were greater in all areas compared to regional cities $(p<0.001)$. The adjusted odds of being involved in a violence incident following the consumption of alcohol was 30.1 times as likely (95\% CI: $27.8-$ $32.6)$ in very remote areas than in regional cities, and 20.7 times as likely (95\% CI: 17.4-24.7) in very remote areas than in regional cities for disorder incidents.

\section{Proportion of people involved in incidents who were recorded as having consumed alcohol prior to the incident}

Geographic area was also a significant predictor variable in the models for the proportion of persons who consumed alcohol prior to violence $\left(\operatorname{LR} \chi^{2}(4)=1,069.78, p<0.001\right)$ and disorder $\left(\operatorname{LR} \chi^{2}(4)=\right.$ $22.53, p<0.001)$ incidents. Comparisons between areas indicated that people in all areas were more likely to have consumed alcohol prior to violence incidents compared to people in regional cities $(p<0.001)$. People in the very remote areas were less likely to have consumed alcohol prior to involvement in disorder incidents $(p=0.01)$ and people in inner regional areas more likely to have done so $(p=0.02)$ compared to those in regional cities. The odds of having consumed alcohol prior to a violence incident was 3.0 times as likely (95\% CI $2.7-3.3)$ in very remote areas than in regional cities. The odds of having consumed alcohol preceding a disorder incident was 1.2 times as likely (95\% CI 1.0-1.4) in inner regional areas than in regional cities, and 0.7 times as likely (95\% CI 0.5-0.9) in very remote areas than in regional cities. 


\section{Proportion of intoxicated people involved in alcohol-related violence and disorder}

Geographic area was a significant predictor variable in the models for intoxication of persons involved in violence $\left(\operatorname{LR} \chi^{2}(4)=74.08\right.$, $p<0.001)$ and disorder $\left(\operatorname{LR} \chi^{2}(4)=15.65, p=0.004\right)$ incidents. People in regional cities who were involved in violence incidents were less likely to be intoxicated compared to those in all other areas $(p<0.001)$, while those people in regional cities who were involved in disorder incidents were less likely to be intoxicated compared to those in inner regional, outer regional, and very remote $(p \leq 0.003)$ areas. The odds of a person in the very remote areas who consumed alcohol prior to involvement in a violence incident being recorded as intoxicated was 1.8 times as likely (95\% CI 1.5-2.1) and 2.6 times as likely (95\% CI 1.4-4.8) for disorder incidents as those people in regional cities.

\section{Day of week of alcohol-related violence and disorder}

Figure 2 displays the proportion of people who consumed alcohol prior to their involvement in violence and disorder incidents by day of week and time of day.

Across all areas, the proportion of people who consumed alcohol prior to their involvement in a violence incident by day of week ranged from Mondays (21.4\%) to Saturdays (51.6\%) (LR $\left.\chi^{2}(6)=2,615.92, p<0.001\right)$. The odds of a person consuming alcohol prior to an incident on Saturdays was 3.9 times as likely (95\% CI 3.6-4.2) than on Mondays. In very remote areas the peak day for alcohol consumption prior to involvement in a violence incident was Fridays, while all other areas experienced a peak on Saturdays.
For disorder incidents, the proportion of people who consumed alcohol prior to the incident ranged from Tuesdays (44.1\%) to Saturdays $(85.8 \%)\left(\operatorname{LR} \chi^{2}(6)=850.58, p<0.001\right)$. The odds of a person consuming alcohol prior to involvement in an incident on Saturdays was 7.5 times as likely (95\% CI 6.0-9.2) than on Tuesdays. A peak in alcohol consumption preceding disorder incidents was recorded on Thursdays in very remote areas and on Saturdays or Sundays in all other areas.

\section{Time of day of alcohol-related violence and disorder}

The proportion of people who consumed alcohol prior to their involvement in a violence incident by time of day ranged from $9 \mathrm{am}-12 \mathrm{pm}(8.4 \%)$ to $12 \mathrm{am}-3 \mathrm{am}(71.8 \%)\left(\mathrm{LR} \chi^{2}(7)=14,686.00\right.$, $p<0.001)$. The odds of prior alcohol consumption between 12 am and 3 am was 28.4 times as likely (95\% CI 25.7-31.4) than between $9 \mathrm{am}-12 \mathrm{pm}$. In all but outer regional areas, the proportion of people who consumed alcohol prior to their involvement in a violence incident peaked between 12 am-3 am. A secondary peak (3 pm-6 pm) occurred in very remote areas.

Across all areas, the proportion of people who consumed alcohol prior to involvement in a disorder incident ranged from 9 am-12 pm $(22.7 \%)$ to $3 \mathrm{am}-6 \mathrm{am}(94.9 \%)\left(\operatorname{LR} \chi^{2}(7)=2,600.80, p<0.001\right)$, with the odds of prior alcohol consumption between 12 am-3 am being 56.4 times as likely (95\% CI 42.8-74.3) than between 9 am$12 \mathrm{pm}$. In very remote areas the proportion of people who consumed alcohol prior to their involvement in a disorder incident peaked earlier (12 am-3 am) compared to almost all other areas (3 am-6 am). A secondary peak ( 3 pm- $6 \mathrm{pm})$ also occurred in very remote areas.

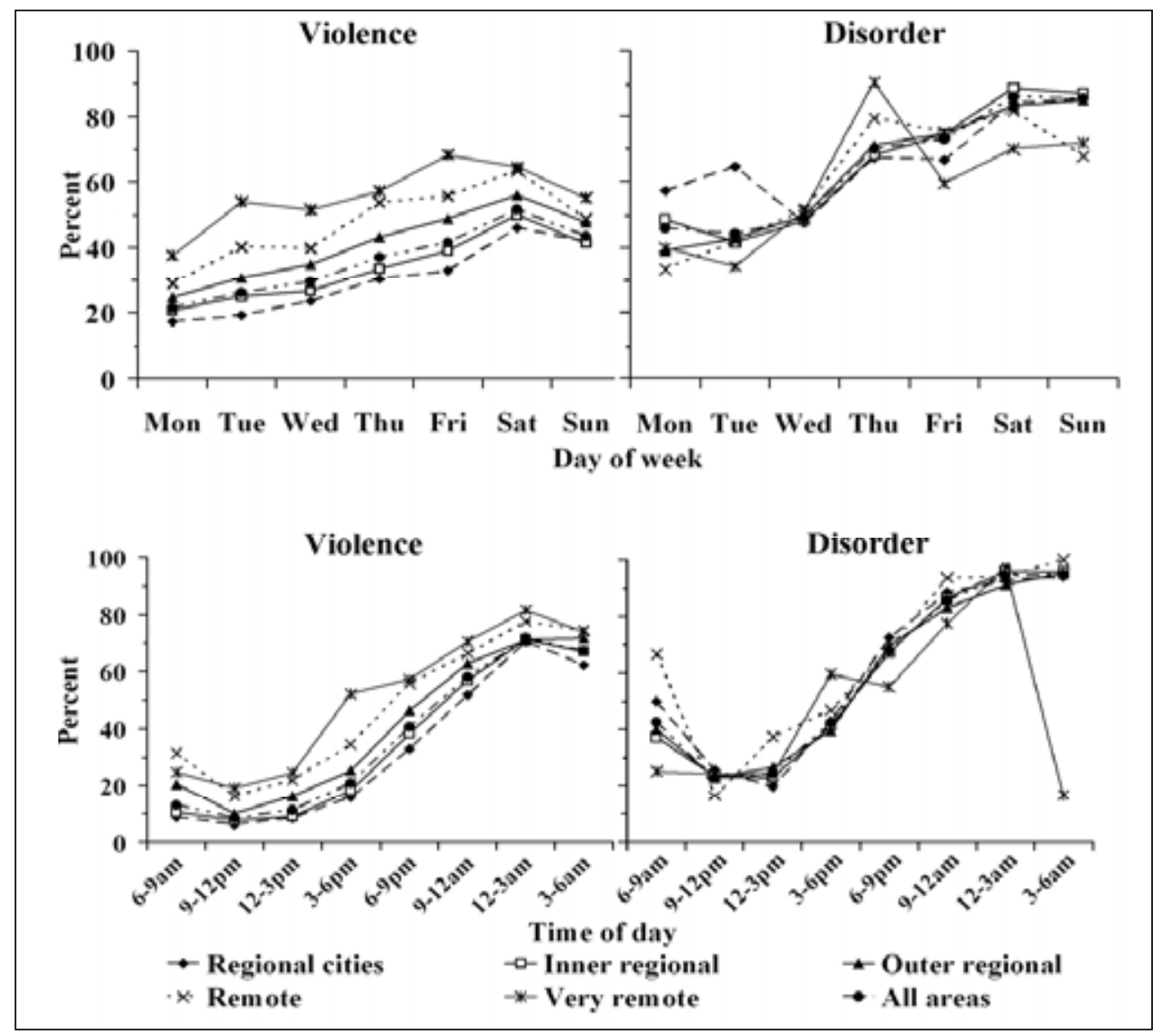

Figure 2: Proportion of people involved in violence and disorder incidents who consumed alcohol prior, by day of week, time of day and geographic area. 


\section{Last place of alcohol consumption}

While across the study area home/private residences and licensed premises were the first and second most commonly recorded last location of alcohol consumption for those involved in a violence incident (Table 2), differences between geographic areas were evident $\left(\chi^{2}(12)=877.65, p<0.001\right)$. In regional cities alcohol was more likely to have been last consumed on licensed premises prior to a violence incident. In all other areas such consumption was more likely to occur in a home/private residence.

Similarly, while across the study area licensed premises and home/private residences were the first and second most commonly recorded last location of alcohol consumption for those involved in a disorder incident, differences between geographic areas were evident $\left(\chi^{2}(12)=274.38, p<0.001\right)$. In regional cities and inner and outer regional areas alcohol was most commonly consumed on licensed premises prior to involvement in a disorder incident. Private residences were the most common last location of alcohol consumption for persons involved in such incidents in remote and very remote areas.

\section{Discussion}

In non-metropolitan areas of NSW alcohol-related crime is a prevalent harm. Across these areas, one in 118 persons in the population consumed alcohol prior to involvement in a policerecorded violence incident and one in $476 \mathrm{did}$ so prior to a disorder incident each year. The greatest burden of such harm occurred in very remote NSW, with a rate of involvement in violence incidents recorded as one in 10 persons. While these incidents most commonly occurred on weekends and late evenings and involved alcohol

\section{Table 2: Last place of alcohol consumption prior to becoming involved in a violence or disorder incident, by geographic area.}

\begin{tabular}{|c|c|c|c|c|}
\hline \multirow[t]{2}{*}{$\begin{array}{l}\text { Geographic } \\
\text { area }\end{array}$} & \multicolumn{4}{|c|}{$\begin{array}{l}\text { Location of last place of alcohol } \\
\text { consumption (\%) }\end{array}$} \\
\hline & $\begin{array}{l}\text { Licensed } \\
\text { premises }\end{array}$ & $\begin{array}{l}\text { Private } \\
\text { residence }\end{array}$ & $\begin{array}{l}\text { Public } \\
\text { place }\end{array}$ & Other \\
\hline \multicolumn{5}{|l|}{ Violence } \\
\hline Regional cities & 48.6 & 44.9 & 4.0 & 2.6 \\
\hline Inner regional & 43.3 & 50.8 & 3.6 & 2.3 \\
\hline Outer regional & 31.9 & 62.7 & 3.2 & 2.1 \\
\hline Remote & 20.7 & 71.1 & 5.8 & 2.4 \\
\hline Very remote & 15.0 & 76.8 & 6.1 & 2.1 \\
\hline All areas & 38.7 & 55.1 & 3.9 & 2.3 \\
\hline \multicolumn{5}{|l|}{ Disorder } \\
\hline Regional cities & 56.5 & 21.1 & 19.1 & 3.3 \\
\hline Inner regional & 66.2 & 22.0 & 8.7 & 3.1 \\
\hline Outer regional & 50.6 & 32.5 & 12.5 & 4.5 \\
\hline Remote & 30.1 & 53.1 & 13.8 & 3.1 \\
\hline Very remote & 23.7 & 44.4 & 26.7 & 5.2 \\
\hline All areas & 57.9 & 26.8 & 11.8 & 3.6 \\
\hline
\end{tabular}

consumed to intoxication in private residences or licensed premises, geographic variability in these characteristics was evident. Such an extensive, yet variable, involvement of alcohol in crime in nonmetropolitan areas suggests a need for further research into the determinants of alcohol use in these areas, and the development of evidence-based interventions tailored to address local determinants and their resultant harm.

The overall proportions of people who were recorded to have consumed alcohol prior to their involvement in incidents of violence (38\%) and disorder (73\%) and the peak day and time for alcoholrelated incidents were consistent with a number of previous police data-based studies. ${ }^{4,6}$ However, such proportions were lower than those reported in two earlier Australian studies. ${ }^{5,7}$ These disparities may be explained by differences between the studies in terms of: the unit of analysis; seasonal variability ${ }^{25}$; the study area; the inclusion of all incidents regardless of severity; or to changes over time. Accordingly, the ability to compare the findings reported in this study with previous studies is limited by methodological differences between the various studies.

Across all geographic areas, intoxication was a common feature of alcohol-related violence and disorder suggesting that intoxication, rather than alcohol consumption per se, may be the more relevant characteristic of alcohol-related crime. Interventions that modify the culture of intoxication in society may therefore be required..$^{26}$

Notwithstanding these consistencies, considerable geographic variability in the data was also evident.

First, and consistent with previous research, ${ }^{4,11-14}$ the population rate of alcohol involvement in violence and disorder incidents increased with increasing remoteness. As income inequality is reportedly associated with greater rates of alcohol-attributed harm, ${ }^{27}$ greater socioeconomic disadvantage in the remote and very remote areas of NSW may account for this finding. ${ }^{16}$ Higher levels of alcohol availability may also explain this finding, with research suggesting a greater density of licensed premises ${ }^{28}$ and greater perceived ease of access to alcohol ${ }^{29}$ in non-metropolitan areas than metropolitan areas.

Second, in contrast to the positive association between the proportional involvement of alcohol in violence incidents and remoteness, an inverse relationship was reported for disorder incidents. Such a finding suggests that differences in the context and circumstances of alcohol consumption and related harm, such as population density and demographic characteristics, number of licensed premises, and urban design may influence the likelihood of an offence occurring and/or being associated with alcohol. ${ }^{27,28,30}$ The influence of the drinking context on this association is further emphasised by the finding of a lower prevalence of alcohol consumption on licensed premises preceding alcohol-related incidents in outer regional and remote areas. As disorder offences occur in public places, alcohol consumed in private residences may represent less of a risk factor for the occurrence and/or recording of disorder offences. Additionally, factors other than alcohol consumption which predict anti-social behaviour and which rise with increasing geographic remoteness, such as drug use and poor community support, ${ }^{31-33}$ may also account for this contrasting finding. 
Third, this study found geographic variability in the characteristics of alcohol-related violence and disorder including an earlier peak in the day (Thursdays and Fridays) and time (12 am-3 am) of alcohol-related violence and disorder incidents in the very remote areas compared to all other areas (weekends and 3 am-6 am). Demographic, social and cultural factors, such as a higher level of reliance on social security entitlements (such entitlements being paid on Thursdays), ${ }^{34}$ and earlier closing times of licensed premises in rural and remote areas may contribute to these differential patterns of association. Restricting alcohol on days in which such entitlements are paid and restricting the volume of off-licence alcohol that may be purchased has been found to be associated with lower levels of alcohol-related harm in remote areas. $^{34}$

The need for the identification of local determinants of alcoholrelated crime is illustrated by the finding that very remote areas experience a secondary peak of alcohol involvement in both violence and disorder incidents ( 3 pm- $6 \mathrm{pm})$. A number of potential factors may account for this finding, including variations in policing practices, ${ }^{35}$ trading hours of liquor outlets ${ }^{34}$ or local alcohol consumption practices. While further research is required to validate this finding, the results highlight a need for the identification of contextual factors and the adoption of flexible approaches to the implementation of evidence-based intervention strategies that address these local determinants of alcohol-related harm. ${ }^{34}$

The results of this study expand understanding of the association between the location of alcohol consumption and the occurrence of alcohol-related crime, an understanding which had previously been limited to analyses of incidents of drink driving. ${ }^{36}$ The observed high prevalence of alcohol consumption in private residences preceding involvement in violence incidents in remote and very remote areas supports more general findings of a strong association between alcohol consumption and domestic violence in these areas. ${ }^{37}$ Similarly, the reported association between drinking on licensed premises and violence incidents in regional city areas is consistent with research indicating that violence perpetrated by an unknown person, which occurs more often in urban environments, ${ }^{38}$ is associated with drinking on licensed premises. ${ }^{8}$

These findings further reinforce the need for harm-reduction strategies to target specific high-risk alcohol consumption contexts. The finding of a high prevalence of drinking in private residences preceding violence incidents suggests that increased alcohol taxation and restricted trading hours of off-licence premises are likely to be effective in reducing alcohol-related violence particularly in the remote and very remote areas where private residences were the most common high-risk drinking context. ${ }^{34}$ Strategies which decrease the affordability or availability of alcohol have strong levels of evidence regarding their effectiveness in reducing both levels of alcohol use and resultant harm and are among the few strategies that may impact alcohol consumption in non-regulated drinking contexts. ${ }^{39}$ The finding that licensed venues were most commonly associated with disorder incidents suggests a need for additional strategies to address alcohol service practices and the trading conditions of licensed premises. Research suggests that the active enforcement of intoxication provisions of the liquor legislation, server liability and limitations on the trading conditions of onlicensed premises can be effective in reducing the harm associated with licensed premises. ${ }^{39}$ Accordingly, the implementation of such strategies, in particular in regional city areas, represent a potential means of reducing harms associated with this drinking context.

In interpreting the results of this study, a number of its design characteristics should be considered.

First, the results demonstrate the benefits of a standardised approach to defining and recording alcohol consumption characteristics of people involved in police-recorded incidents. The proportion of people across the study area for whom alcohol consumption characteristics were recorded was high relative to other studies ${ }^{6}$ with only limited variability in the recording of alcohol information across the study area.

Second, the exclusion in this study of those people whose alcohol consumption data was missing may have resulted in either an over or an under-estimate (by a maximum of 7\%) of the prevalence of prior alcohol consumption in incidents. Furthermore, the known underreporting of alcohol-related incidents to police, ${ }^{40}$ suggests that, as with all agency data, ${ }^{17}$ the rates reported in this study are likely to represent only a fraction of the total number of people experiencing such harm. Accordingly, the study findings suggest that the impact of such harm on individuals, families and the community represents a significant public health burden in non-metropolitan NSW.

Third, the validity and reliability of the recording procedures utilised in this study have not been determined. However, previous studies have reported high sensitivity and specificity of self-reported alcohol consumption, ${ }^{41}$ and police officers' assessment of prior alcohol consumption and intoxication..$^{21,42}$ Information regarding the location of alcohol consumption prior to an incident is subject to the limitations of self-report by persons experiencing varying degrees of intoxication. Nonetheless, the data currently represent the best available information regarding the drinking contexts associated with police-recorded incidents. ${ }^{18}$

Fourth, as this study was conducted in one non-metropolitan area of Australia, the generalisability of the study findings is unknown. However, despite a slightly higher proportion of males, a characteristic of non-metropolitan areas of Australia generally, ${ }^{22}$ the population characteristics of the study area approximate those of the non-metropolitan areas of NSW and Australia generally. ${ }^{22}$ Furthermore, despite minor changes to the liquor laws and liquor licenses, public health campaigns and local initiatives that have occurred since the study period, ${ }^{26,43-46}$ population surveys report that patterns of alcohol consumption across non-metropolitan NSW have remained stable over recent years, ${ }^{47}$ suggesting that the impact of these interventions on the reported findings are likely to be minimal.

Finally, differential policing activity between geographic areas ${ }^{35}$ and the greater informality of policing in remote areas ${ }^{48}$ could have influenced the study findings. The extent to which police activity differed between areas during the study period is unknown.

Improvement in the information recorded by police has enabled an analysis of, and comparison between, the prevalence and characteristics of alcohol involvement in violence and disorder incidents in non-metropolitan NSW. The findings of this study 
suggest that such harm occurs at high levels in these areas. Furthermore, this data represents important intelligence upon which further evidence can be gained to guide the development of specific locally targeted evidence-based interventions to reduce the burden associated with alcohol-related crime in these communities.

\section{Acknowledgements}

The contributions of Dr Patrick McElduff, Assistant Commissioner Robert J Waites and the officers of NSW Police Force to this project are appreciated. The Alcohol Education \& Rehabilitation Foundation funded this project.

\section{References}

1. Collins DJ, Lapsley HM. The Costs of Tobacco, Alcohol and Illicit Drug Abuse to Australian Society in 2004/05. National Drug Strategy Monograph No. 66. Canberra (AUST): Commonwealth Department of Health and Ageing; 2008.

2. Chikritzhs T, Catalano P, Stockwell T, et al. Australian Alcohol Indicators, 1990-2001: Patterns of Alcohol Use and Related Harms for Australian States and Territories. Perth (AUST): Curtin University, National Drug Research Institute; 2003.

3. Middleton J. Crime is a public health problem. Med Confl Surviv. 1998;14(1):24-8.

4. Briscoe S, Donnelly N. Temporal and regional aspects of alcohol-related violence and disorder. Alcohol Studies Bulletin. 2001;1:1-15.

5. Ireland CS, Thommeny JL. The crime cocktail: licensed premises, alcohol and street offences. Drug Alcohol Rev. 1993;12: 143-50.

6. Arro P, Crook G, Fenlon T. The Nature and Extent of Alcohol Related Incidents Requiring Police Attention in South East Queensland: Results of an Alcohol Management Study. Brisbane (AUST): Department of Health and Queensland Police Service; 1992.

7. English DR, Holman CDJ, Milne E, et al. The Quantification of Drug Caused Morbidity and Mortality in Australia. 1995 ed. Canberra (AUST): Commonwealth Department of Human Services and Health; 1995.

8. Budd T. Alcohol-related Assault: Findings from the British Crime Survey. London (UK): Home Office; 2003.

9. Poynton $S$, Donnelly N, Weatherburn D, Fulde G. The role of alcohol in injuries presenting to St Vincent's Hospital emergency department and the associated short-term costs. Alcohol Studies Bulletin. 2005;6:1-16.

10. United States General Accounting Office. Rural Drug Abuse: Prevalence, Relation to Crime and Programs. Report to Congressional Requesters. Washington (DC): US GAO; 1990.

11. Midford R, Masters L, Phillips M, et al. Alcohol consumption and injury in Western Australia: a spatial correlation analysis using geographic information systems. Aust N Z J Public Health. 1998;22(1):80-5.

12. Price B. Bourke Local Government Area Crime Report 2007. Sydney (AUST): New South Wales Bureau of Crime Statistics and Research; 2009.

13. Jonas H, Dietze P, Rumbold G, Hanlin K, Cvetkovski S, Laslett A. Associations between alcohol related hospital admissions and alcohol consumption in Victoria: influence of socio-demographic factors. Aust N Z J Public Health. 1999;23(3):272-9.

14. New South Wales Office of Liquor, Gaming and Racing. Social Profile Report Series. Sydney (AUST): OLGR; 2009.

15. Stevenson RJ, Lind B, Weatherburn W. The relationship between alcohol sales and assault in New South Wales, Australia. Addiction. 1999;94(3):397-410.

16. Population Health Division. The Health of the People of New South Wales - Report of the Chief Health Officer. Sydney (AUST): New South Wales Department of Health; 2008

17. Stockwell T, Chikritzhs T, Brinkman S. The role of social and health statistics in measuring harm from alcohol. J Subst Abuse. 2000;12:139-54.

18. Marsh P, Bradley S, Peck F, Carnibella A. Counting the Cost: The Measurement and Recording of Alcohol-related Violence and Disorder. London(AUST): The Portman Group; 2002.

19. Doherty SJ, Roche AM. Alcohol and Licensed Premises: Best Practice in Policing. Melbourne (AUST): Australasian Council for Policing Research; 2003.

20. Wiggers J, Jauncey M, Considine R, et al. Strategies and outcomes in translating alcohol harm reduction research into practice: the alcohol linking program. Drug Alcohol Rev. 2004;23:355-64.

21. Teplin LA, Lutz GW. Measuring alcohol intoxication: the development, reliability and validity of an observational instrument. Journal of Studies on Alcohol. 1985;46(6):459-66.
22. Australian Bureau of Statistics. 2001 Census of Population and Housing CDATA 2001. Canberra (AUST): ABS; 2004.

23. Doak P, Fitzgerald J, Ramsay M. New South Wales Recorded Crime Statistics 2002. Sydney (AUST): New South Wales Bureau of Crime Statistics and Research; 2003.

24. New South Wales Office of Liquor, Gaming \& Racing. Intoxication Guidelines. Sydney (AUST): NSW OLGR; 2008.

25. Jochelson R. Crime and Place: An Analysis of Assaults and Robberies in Inner Sydney. Sydney (AUST): New South Wales Bureau of Crime Statistics and Research; 1997.

26. Ministerial Council on Drug Strategy. National Alcohol Strategy 2006-2009: Towards Safer Drinking Cultures. Canberra (AUST): Commonwealth of Australia; 2006.

27. Dietze PM, Jolley DJ, Chikritzhs TN, Clemens S, Catalano P, Stockwell T. Income inequality and alcohol attributed harm in Australia. BMC Public Health. 2009;9:70-9.

28. Stevenson RJ, Lind B, Weatherburn D. The relationship between alcohol sales and assault in New South Wales, Australia. Addiction. 1999;94;397-410.

29. Cooper-Stanbury M, Nargis S. Correlates of risky alcohol consumption in regional and remote Australia. Proceedings of the 10th National Rural Health Conference; 2009 May 17-20; Cairns, AUST.

30. Bromley RDF, Nelson AL. Alcohol-related crime and disorder across urban space and time: evidence from a British city. Geoforum. 2002;33:239-54.

31. McAtamney A, Morgan A. Key Issues in Antisocial Behaviour. Canberra (AUST): Australian Institute of Criminology; 2009.

32, Australian Institute of Health and Welfare. 2007 National Drug Strategy Household Survey: Detailed Findings. Canberra (AUST): AIHW; 2008.

33. Australian Institute of Health and Welfare. Mental Health Services in Australia 2006-07. Canberra (AUST): AIHW; 2009.

34. National Drug Research Institute. Restrictions on the Sale and Supply of Alcohol: Evidence and Outcomes. Perth (AUST): Curtin University, NDRI; 2007.

35. Matka E. Uses and abuses of crime statistics. BOCSAR NSW Crime and Justice Bulletin. 1997;11:1-8.

36. Wood LJ, McLean S, Davidson J, Montgomery IM. One for the road: on the utility of citation data for identifying problem hotels. Drug Alcohol Rev. 1995; 14:115-24.

37. People J. Trends and patterns in domestic violence assaults. BOCSAR NSW Crime and Justice Bulletin. 2005;89:1-16.

38. Smith MD, Parker RN. Type of homicide and variation in regional rates. Journal of Social Forces. 1980;59(1):136-47.

39. Babor T, Caetano R, Casswell S, et al. Alcohol: No Ordinary Commodity Research and Public Policy. 2nd ed. Oxford (UK): Oxford University; 2010.

40. Bryant M, Williams P. Alcohol and other drug-related violence and nonreporting. Trends and Issues in Crime and Criminal Justice. 2000;171:1-6.

41. Cherpitel CJS, Parés A, Rodés J, Rosovsky H. Validity of self-reported alcohol consumption in the emergency room: data from the United States, Mexico and Spain. Journal of Studies on Alcohol. 1992;53(3):203-7.

42. Grossman DC, Mueller BA, Kenaston T, Salzberg P, Cooper W, Jukovich GJ. The validity of police assessment of driver intoxication in motor vehicle crashes leading to hospitalization. Accid Anal Prev. 1996;28(4):435-42.

43. New South Wales Office of Liquor Gaming and Racing. New Liquor Laws in NSW. Sydney (AUST): NSW OLGR; 2008.

44. New South Wales Office of Liquor Gaming and Racing. Statistics: Fast Facts 2009. Sydney; NSW OLGR; 2009.

45. Jones C, Kypri K, Moffatt S, Borzycki C, Price B. The impact of restricted alcohol availability on alcohol-related violence in Newcastle, NSW. BOCSAR NSW Crime and Justice Bulletin. 2009;137:1-24.

46. Moffatt S, Mason A, Borzycki C, Weatherburn D. Liquor Licensing Enforcement and Assaults on Licensed Premises. Bureau Brief No. 40. Sydney (AUST): NSW Bureau of Crime Statistics and Research; 2009.

47. Centre for Epidemiology and Research. 2008 Report on Adult Health from the New South Wales Population Health Survey. Sydney (AUST): New South Wales Department of Health; 2009.

48. Jobes PC. Human ecology and rural policing: a grounded theoretical analysis of how personal constraints and community characteristics influence strategies of law enforcement in rural New South Wales, Australia. Police Practice and Research. 2003;4(1):3-19. 
Copyright of Australian \& New Zealand Journal of Public Health is the property of Wiley-Blackwell and its content may not be copied or emailed to multiple sites or posted to a listserv without the copyright holder's express written permission. However, users may print, download, or email articles for individual use. 